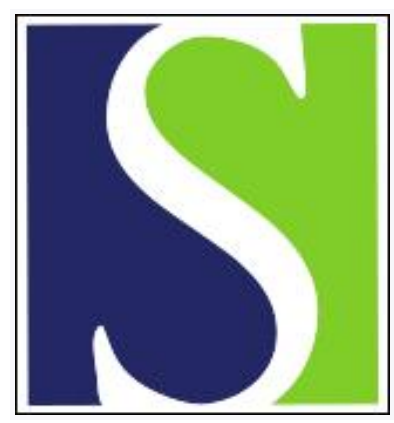

Scand J Work Environ Health 2016;42(1):43-51

https://doi.org/10.5271/sjweh.3540

Published online: 09 Dec 2015, Issue date: 01 Jan 2016

Multi-wave cohort study of sedentary work and risk of ischemic heart disease

by Møller SV, Hannerz H, Hansen AM, Burr H, Holtermann A

This is a study with high validity, several exposure measures and high statistical power that rejects the hypotheses that occupational sitting time is a distinct risk factor for ischemic heart disease when the effect of occupational sitting is disentangled from that of occupational physical activity, which is a weakness of the majority of prior studies within this field.

Affiliation: National Research Centre for the Working Environment, Lersø Parkallé 105, 2100 Copenhagen O, Denmark. aho@nrcwe.dk

The following article refers to this text: 2018;44(1):96-105

Key terms: cohort; cohort study; DAG; directed acyclic graph; IHD; ischemic heart disease; multi-wave cohort study; sedentary behavior; sedentary lifestyle; sedentary work

This article in PubMed: www.ncbi.nlm.nih.gov/pubmed/26649851 


\title{
Multi-wave cohort study of sedentary work and risk of ischemic heart disease
}

\author{
by Simone Visbjerg Møller, MSc, ${ }^{1}$ Harald Hannerz, PhD, ${ }^{1}$ Åse Marie Hansen, PhD, ${ }^{1,2}$ Hermann Burr, \\ $P h D,{ }^{3}$ Andreas Holtermann, $P h D^{1}$
}

\begin{abstract}
Møller SV, Hannerz H, Hansen ÅM, Burr H, Holtermann A. Multi-wave cohort study of sedentary work and risk of ischemic heart disease. Scand J Work Environ Health. 2016;42(1):43-51. doi:10.5271/sjweh.3540

Objectives This study aimed to investigate whether sedentary work is a distinct risk factor for ischemic heart disease (IHD) when the effect of occupational sitting is disentangled from that of occupational physical activity.

Methods Data on occupational sitting time and several covariates were derived from the Danish Work Environment Cohort Study (DWECS) conducted every five years from 1990-2005 among the active Danish population. This study was designed as a multi-wave longitudinal study including participants employed at entry. Respondents were followed in national registers, first for death or hospital treatment due to IHD and second for purchase of medication that may prevent IHD from (re)occurring serving as a proxy for IHD.
\end{abstract}

Results During 145850 person-years of follow-up, 510 cases of fatal and non-fatal IHD occurred. After adjustment for age, sex, body mass index (BMI), and socioeconomic status, no difference in risk of IHD was observed between sedentary and non-sedentary employees [hazard ratio (HR) $0.95,95 \%$ confidence interval $(95 \% \mathrm{CI})$ 0.78-1.16]. During 44949 and 42456 person-years of follow-up among men and and women, respectively, 1263 men and 1364 women purchased IHD-related medication. No differences in risk were observed between sedentary and non-sedentary participants, either for men or women. A dose-response relationship between occupational sitting time and the risk of IHD was also not detected.

Conclusions This study could not confirm the hypothesis that sedentary work is a distinct risk factor for IHD. Future studies may further investigate the association with objective measures of occupational sitting time.

Key terms DAG; directed acyclic graph; IHD; ischemic heart disease medication; occupational sitting; sedentarism; sedentary behavior; sedentary lifestyle.

Over the past decade, research within the physical activity and public health field has increasingly focused on sedentary behaviors, defined as any waking behavior characterized by an energy expenditure $\leq 1.5$ metabolic equivalent of task (MET) while in sitting or reclining posture (1). Several studies have demonstrated the deleterious effects that sedentary behaviors have on a number of health outcomes, such as cardiovascular disease, diabetes, and mortality (2-6). These effects have been shown to be different from those attributed to the lack of moderate-to-vigorous-intensity physical activity $(7,8)$. Hence, sedentary behavior is suggested to be an independent health risk factor rather than simply one extreme on the physical activity continuum (8).
In particular, the link between leisure-time sedentary behaviors, such as TV viewing, and the risk of cardiovascular disease has been established in the literature (9-12). However, not all domains of sedentary behavior seem to have the same impact on cardiovascular outcomes. Two cross-sectional studies found the associations between occupational sitting time and cardio-metabolic risk factors to be fewer and weaker compared to leisure-time sitting $(13,14)$. Also in van Uffelen and colleagues' systematic review (15), only limited evidence was found to support a relationship between occupational sitting and health risks in general, and the identified papers investigating cardiovascular disease even revealed conflicting results. Most of these

1 National Research Centre for the Working Environment, Copenhagen, Denmark.

2 Department of Public Health, University of Copenhagen, Copenhagen, Denmark.

3 Bundesanstalt für Arbeitsschutz und Arbeitsmedizin (BAuA), Berlin, Germany.

Correspondence to: Andreas Holtermann, National Research Centre for the Working Environment, Lersø Parkallé 105, 2100 Copenhagen O, Denmark. [E-mail: aho@nrcwe.dk] 
studies used a categorical self-report measure of occupational physically activity with sedentary, mainly sitting, or physically-very-easy sitting office work as the response variable representing sedentary work. As noted by Yates et al (16) these ordinal scales of occupational physical activity are not necessarily ordinal scales of occupational sitting, as high levels of sedentary behavior at work can co-exist with high levels of occupational physical activity. Considering the different effects of these behaviors, the use of estimates of occupational physical activity to make inferences about the impact of sedentary work is likely to introduce substantial misclassification bias.

Taking into account the weekly hours of occupational sitting, the aim of the present study was to test the hypotheses that (i) employees engaged in sedentary work have a higher risk of ischemic heart disease (IHD) compared to employees not engaged in sedentary work, and (ii) a positive dose-response relationship exists between occupational sitting time and the risk of IHD.

\section{Methods}

\section{Study design}

We conducted a multi-wave follow-up study within the Danish Work Environment Cohort Study (DWECS) by linking data on sitting time and covariates from the four waves $1990,1995,2000$, and 2005 to national registers via the participants' unique civil registration number. Purchase of prescription for IHD-related medication has been shown to be a good risk indicator of IHD in the working population in Denmark (17). IHD-related medication was included in the study as a second endpoint in addition to IHD-related hospital admission, in order to increase the statistical power of the analyses.

The follow-up period for death or hospitalization due to IHD ran from 1 January 1991 to 31 December 2010 and included all four waves. The follow-up period for purchases of prescribed IHD-related medication, serving as a proxy for IHD, ran from 1 January 1996 to 31 December 2010, and included the waves 1995, 2000, and 2005.

For each endpoint, all participants were followed until any of the following events occurred: he/she reached the clinical endpoint of the follow-up, he/she emigrated from Denmark, he/she died from primary causes other than IHD, or the study period ended.

\section{Study cohort}

DWECS was an open dynamic cohort with a split panel design drawn from a representative sample of the active Danish population (18). A main panel and additional age and migration panels were drawn from the Civil Registration System. The main panel consisted of a random sample of people aged 18-59 years as of 1 October 1990, who were invited for a telephone interview in October-November 1990. An additional panel was randomly drawn from a population of people aged $18-59$ years in 2005 . At each wave, the population was supplemented with age (18-22 years) and migration (immigrated within the last five years prior to cohort entry) panels to remain representative of the Danish workforce. Once a subject was drawn for a certain panel and invited for the study, he/she was re-invited at all subsequent waves, irrespective of participation at previous waves. Interviews were conducted by telephone in 1990, 1995, and 2000 and by a combination of postal questionnaire $(90 \%)$ and telephone interviews $(10 \%)$ in 2005 . Response rates in the study were high, but decreased continuously from $90 \%$ in 1990 to $63 \%$ in 2005. Feveile et al (18) have published details of DWECS.

Respondents to the DWECS, who were categorized as employees according to the interview in 1990, entered the cohort on 1 January 1991 if on that date they: (i) lived in Denmark, were $\geq 21$ years old, and were free from the respective clinical endpoints throughout the calendar year preceding baseline (ie, in order to pursue a design where the exposure is measured before the outcome is developed). The same principle was used for new entries among respondents interviewed during the 1995, 2000, and 2005 waves.

\section{National registers}

Information on IHD was obtained from the Danish Occupational Hospitalisation Register (OHR) and information on IHD-related medication from the Danish National Prescription Registry.

OHR is a database obtained through record-linkage between the Civil Registration System, the Danish National Patient Register, the Cause of Death Register, and the Employment Classification Module. OHR includes every person who at some point since 1980 has been living and working in Denmark. The Danish National Patient Register has existed since 1977 and contains data from all public hospitals in Denmark ( $>99 \%$ of all admissions). Diagnoses were coded according to the International Classification of Disease, $8^{\text {th }}$ revision (ICD-8) before 1994, after which the ICD-10 was used (19).

The Danish National Prescription Registry contains all purchases of prescription drugs at pharmacies in Denmark since 1995 (20). 


\section{Occupational sitting time}

Occupational sitting was measured at all four waves of DWECS with the item "Does your job involve sitting?" and the following six response categories: (i) almost all of the time; (ii) approximately $3 / 4$ of the time; (iii) approximately $1 / 2$ of the time; (iv) approximately $1 / 4$ of the time; (v) rarely; and (vi) never. Since this operationalization of occupational sitting does not provide absolute values of sitting hours, the categories of sitting time were converted into corresponding constants $(0.875,0.75,0.5,0.25,0.125$, and 0$)$ and combined with self-reported information on actual weekly working hours in main and second jobs. Eriksen et al (21) have published a similar measure of occupational sitting time.

Moreover the weekly occupational sitting time was defined on an ordinal scale with five categories $(0,>0$ $<10,10-<20,20-<30$, and $\geq 30$ hours).

\section{Sedentary work}

In previous studies, employees are considered to be exposed to sedentary work if they report a minimum of $3 / 4$ of their working time is spent sitting due to a particular health risk when exceeding this threshold (22). In the present study, participants are categorized as sedentary at work if they spend $\geq 25$ hours sitting at work per week, accounting for participants having varying number of working hours. When applying this cut point, part-time employees (usually working 30 hours per week) who have stated they sit almost all of the time are included in the exposed category.

\section{Ischemic heart disease and IHD-related medication}

The following two endpoints were considered separately, in accordance with Hannerz et al (23): (i) IHD: hospital treatment or death with IHD as principal diagnosis/cause of death. The case definitions include the following ICD codes: 410-414 (ICD-8) and I20-I25 (ICD-10); (ii) IHD-related medication: purchase of prescription for medications that may prevent IHD from (re)occurring. The case definitions includes these ATC-codes: C01A cardiac glysocides, C01D vasodilators used in cardiac diseases, $\mathrm{C} 02$ antihypertensiva, $\mathrm{C} 03$ diuretics, C07 alpha- and beta-blockers, C08 calcium channel blockers, C09 ACE-inhibitors and angiotensinII antagonists, and C10 lipid-modifying agents.

\section{Potential confounders and modifiers}

Potential confounders and mediators of the association between sedentary work and IHD were identified in the existing scientific literature on general sedentary behavior and cardiovascular disease. Decisions on which confounders to include in the analyses were taken in accordance with the theory of directed acyclic graphs (DAG) (24), see figure 1.

Information on age and gender was obtained from the Civil Registration System. Socioeconomic status (SES) was provided by Statistics Denmark and is defined according to the respondents' term of employment and classified into three groups of white-collar and two groups of blue-collar workers (25).

At all four DWECS waves, the respondents have indicated their smoking status as current, former, or never smoker. BMI is calculated at each wave using respondents' self-reported height and weight.

Only at the waves 2000 and 2005 were respondents asked about their diet, alcohol consumption, and level of leisure-time physical activity. The questions and response categories regarding leisure-time physical activity did not have the exact same wording at the waves 2000 and 2005. However, it was possible to dichotomize the two variables so that they both indicate whether or not respondents are physically inactive ( $>2$ hours of moderate physical activity per week). In 2000, alcohol consumption was measured as the number of unit wine, beers and spirits consumed per day. In 2005 alcohol consumption was measured as average units consumed per week days and per days in the weekend. The variables have been dichotomized indicating high risk consumers, which is consumption $>14$ units per week for women and $\geq 21$ units per week for men, according to the threshold set by the Danish Health and Medicines Authority (26).

Decision latitude, a dimension of job control found to influence risk of myocardial infarction (27), was measured at all DWECS waves with the item "Do you have great influence over decisions regarding your work?" and the response categories: always; usually; usually not; never.

\section{Statistical analysis}

The association between sedentary work, occupational sitting time, and relative rate (RR) of IHD was analyzed using multiple Poisson regressions. A chi ${ }^{2}$ goodness-offit test was performed using the ordinal scale of occupational sitting time in order to determine a possible dose- response relationship.

Person-years at risk were calculated for each individual, first for test of IHD and then IHD-related medication.

Since the exposure variable is measured at four waves, the exposure status can change over time. In case of a missing data point of an exposure or confounder variable at a certain wave, the most recent available information was carried forward. Carry backward was avoided to reduce the risk of reverse causality, that is, the onset disease affecting the level of occupational sitting time or the confounders. Thus, variables only avail- 


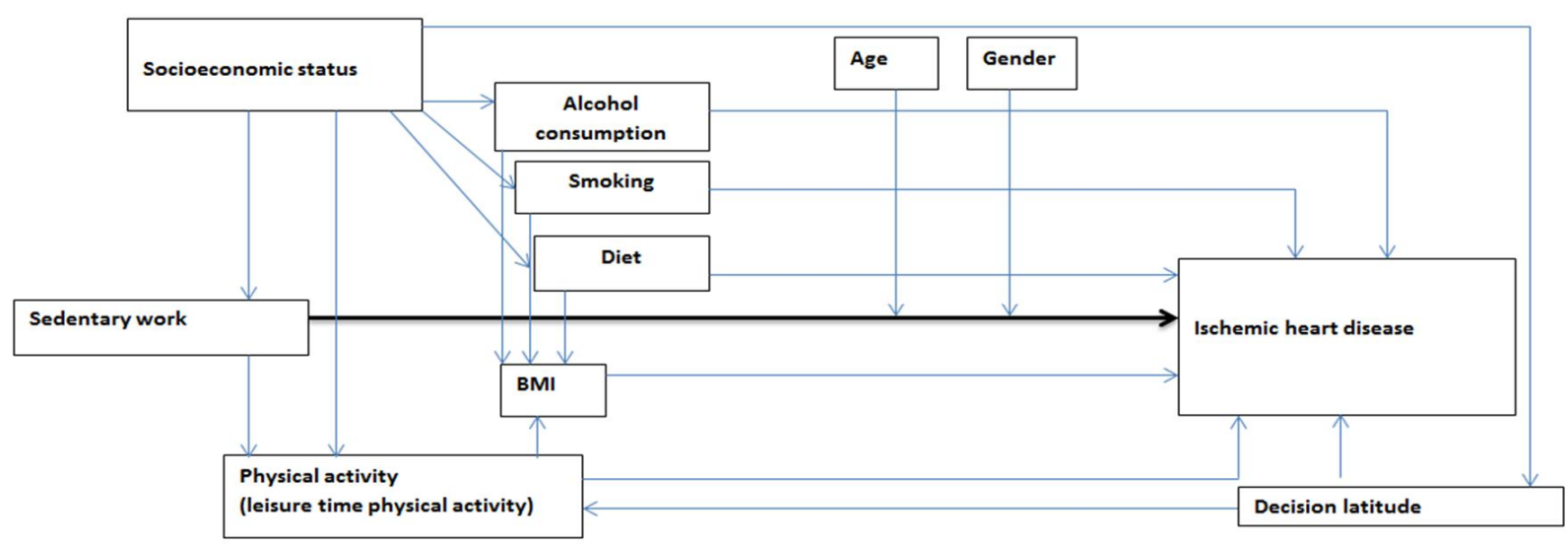

Figure 1. A directed acyclic graph (DAG) representing the theoretical framework of the relationship between sedentary work and ischemic heart disease

able at the 2000 and 2005 waves could not be included in the main analyses with follow-up beginning in 1991. Instead, they were included in sensitivity analyses with a follow-up period beginning in 2001.

According to the theory of DAG, it would be sufficient to adjust the analyses for SES and wave, and stratify on age, gender and physical activity. Confounding effects of other health behaviors and BMI are already taken into account when adjusting for SES. However, due to low statistical power some deviations from this optimal design were made. Age was instead treated as a confounder in all analyses and gender was treated as a confounder when studying IHD. Because physical activity is not available before the 2000 wave, BMI was treated as a confounder in the main analyses as a proxy of physical activity. Sensitivity analyses included physical activity and were further adjusted for smoking status, alcohol consumption and decision latitude.

The hypothesis and the statistical models were completely defined in a detailed study protocol before any relation between the concerned exposure and response variables in the data material were studied. Statistical analyses were performed with the software SAS, version 9.3 (SAS Institute, Cary, NC, USA).

\section{Results}

Table 1 presents the characteristics of DWECS participants included in the analyses when followed for IHD from 1991-to 2010 (1990, 1995, 2000, and 2005 waves). Table 2 presents the participants included in the corresponding sensitivity analysis when followed from 2001-2010 (2000 and 2005 waves).

Throughout the study period from 1991-2010, a total of 11996 participants contributed with 145850 person- years of follow-up (mean 12.16 years). In this period, 510 IHD cases occurred. When participants were followed for IHD-related medication from 2001-2010, a total of 5095 men contributed with 44949 person-years of follow-up (mean 7.5 years) and 5218 women contributed with 42 456 person-years of follow-up (mean 8.14 years). In this period, 1263 men and 1364 women purchased prescribed IHD-related medication during follow-up.

Table 3 presents the Poisson proportional hazards regression analyses for associations between sedentary work, occupational sitting time and incidence of IHD. No differences in the RR of IHD were found between sedentary and non-sedentary participants when adjusting for gender, age, BMI and SES: RR=0.95 $(95 \% \mathrm{CI}$ $0.78-1.16$ ). Results were consistent when further adjusting for health behaviors and decision latitude: $\mathrm{RR}=0.94$ (95\% CI 0.71-1.27). For every 10 hours increase in occupational sitting time, the RR for IHD was 0.99 (95\% CI 0.92-1.06).

Results from the analyses of associations between sedentary work, occupational sitting time, and purchase of prescribed IHD-related medication are presented in table 4. No differences could be observed in the RR of purchasing IHD-related medication when comparing sedentary and non-sedentary participants, either among men $(\mathrm{RR}=1.00,95 \% \mathrm{CI} 0.88-1.13)$ or women $(\mathrm{RR}=0.93$, 95\% CI 0.82-1.06).

The goodness-of-fit tests yielded similar results and found no association between occupational sitting time and IHD as well as purchase of IHD-related medication (data not shown).

Due to SES being strongly correlated with occupational sitting, inclusion of SES as a confounder may lead to an overcorrection of the effect sizes. Therefore, additional post-hoc sensitivity analyses for IHD were performed without adjustment for SES and stratified on SES, respectively. When adjusting for gender, age and 
Table 1. Characteristics of participants in the dynamic Danish Work Environment Cohort Study (DWECS) cohort followed from 1991-2010 for ischemic heart disease.

\begin{tabular}{|c|c|c|c|c|c|c|c|c|}
\hline & \multicolumn{8}{|c|}{ Wave } \\
\hline & \multicolumn{2}{|c|}{1990} & \multicolumn{2}{|c|}{1995} & \multicolumn{2}{|c|}{2000} & \multicolumn{2}{|c|}{2005} \\
\hline & $\mathrm{N}$ & $\%$ & $\mathrm{~N}$ & $\%$ & $\mathrm{~N}$ & $\%$ & $\mathrm{~N}$ & $\%$ \\
\hline Total & 5420 & 100 & 6423 & 100 & 7139 & 100 & 10821 & 100 \\
\hline \multicolumn{9}{|l|}{$\begin{array}{l}\text { Sedentary work ( } \geq 25 \text { hours spent sitting } \\
\text { at work per week) }\end{array}$} \\
\hline Yes & 1707 & 31.5 & 2009 & 31.3 & 2273 & 31.8 & 3620 & 33.5 \\
\hline No & 3713 & 68.5 & 4414 & 68.7 & 4866 & 68.2 & 7201 & 66.5 \\
\hline \multicolumn{9}{|l|}{ Age (years) } \\
\hline $21-39$ & 2737 & 50.5 & 2706 & 42.1 & 2514 & 35.2 & 3001 & 27.7 \\
\hline $40-49$ & 1597 & 29.5 & 1815 & 28.3 & 1864 & 26.1 & 3133 & 29.0 \\
\hline $50-59$ & 1004 & 18.5 & 1405 & 21.9 & 1735 & 24.3 & 2865 & 26.5 \\
\hline $60-69$ & 82 & 1.5 & 497 & 7.7 & 959 & 13.4 & 1441 & 13.3 \\
\hline$\geq 70$ & 0 & 0.0 & 0 & 0.0 & 67 & 0.9 & 381 & 3.5 \\
\hline \multicolumn{9}{|l|}{ Gender } \\
\hline Women & 2594 & 47.9 & 3167 & 49.3 & 3606 & 50.5 & 5622 & 52.0 \\
\hline Men & 2826 & 52.1 & 3256 & 50.7 & 3533 & 49.5 & 5199 & 48.0 \\
\hline \multicolumn{9}{|l|}{ Socioeconomic status } \\
\hline Social class I (highest) & 713 & 13.2 & 868 & 13.5 & 1023 & 14.3 & 1703 & 15.7 \\
\hline Social class II & 1041 & 19.2 & 1009 & 15.7 & 1257 & 17.6 & 2358 & 21.8 \\
\hline Social class III & 1986 & 36.6 & 2465 & 38.4 & 2471 & 34.6 & 3074 & 28.4 \\
\hline Social class IV & 555 & 10.2 & 700 & 10.9 & 815 & 11.4 & 1591 & 14.7 \\
\hline Social class V (lowest) & 1125 & 20.8 & 1381 & 21.5 & 1573 & 22.0 & 2095 & 19.4 \\
\hline \multicolumn{9}{|l|}{ BMI $\left(\mathrm{kg} / \mathrm{m}^{2}\right)$} \\
\hline Normal/underweight $(<25)$ & 3868 & 71.4 & 4305 & 67.0 & 4303 & 60.3 & 6144 & 56.8 \\
\hline Overweight $(25-<30)$ & 1295 & 23.9 & 1745 & 27.2 & 2271 & 31.8 & 3600 & 33.3 \\
\hline Obese $(\geq 30)$ & 257 & 4.7 & 373 & 5.8 & 565 & 7.9 & 1077 & 9.9 \\
\hline \multicolumn{9}{|l|}{ Year of cohort entry } \\
\hline 1991 & 5420 & 100 & 5320 & 82.8 & 5155 & 72.2 & 4909 & 45.4 \\
\hline 1996 & . & . & 1103 & 17.2 & 1110 & 15.5 & 1104 & 10.2 \\
\hline 2001 & . & . & . & . & 874 & 12.2 & 897 & 8.3 \\
\hline 2006 & . & . & . & . & . & . & 3911 & 36.1 \\
\hline
\end{tabular}

BMI only, sedentary participants had a $\mathrm{RR}=0.89(95 \%$ CI $0.74-1.08)$ of IHD incidences compared to nonsedentary participants. Likewise, the stratified analyses showed no differences in RR of IHD between sedentary and non-sedentary participants, neither among participants with SES (SES groups I-III: $\mathrm{RR}=0.97$, 95\% CI 0.76-1.23) nor among participants with low SES (SES group IV and V: RR=0.90, 95\% CI 0.37-1.32).

In response to a comment by the reviewer, we performed two post hoc sensitivity analyses, one with hospital contacts due to IHD and one with IHD-related medications as outcome. For the IHD, we only included people who lived in Denmark and were free from hospital contacts due to IHD throughout the time period between 1 January 1991 and entry into the cohort $(\mathrm{N}=6202)$. For IHD-related medications, we only included people who lived in Denmark and who did not redeem any prescription for IHD-related medication between 1 January 1995 and entry into the cohort (4309 men and 4255 women). The obtained rate ratios were 0.96 (95\% CI 0.77-1.20) for hospital contacts due to IHD, 1.00 (95\% CI 0.88-1.14) for IHD-related medications among men, and 0.96 (95\% CI 0.84-1.09) for IHD-related medications among women.

\section{Discussion}

We hypothesized that employees engaged in sedentary work are exposed to an increased risk of IHD compared to employees not engaged in sedentary work. This hypothesis could not be confirmed. When adjusting for age, gender, SES, BMI and wave, no difference in risk of IHD was observed between sedentary and nonsedentary employees. Also, when studying purchase of IHD-related medication as a proxy for risk of IHD, no differences were observed between the two groups, either for men or women. Furthermore, we hypothesized that a dose-response relationship exists between time spent sitting at work and the risk of IHD. In the study protocol, we planned to test this with the goodnessof-fit test. However, since no linear relations could be observed in the regression analyses, the goodness-of-fit 
Table 2. Characteristics of participants in the dynamic Danish Work Environment Cohort Study (DWECS) cohort followed from 2001-2010 for ischemic heart disease.

\begin{tabular}{|c|c|c|c|c|}
\hline & \multicolumn{4}{|c|}{ Wave } \\
\hline & \multicolumn{2}{|c|}{2000} & \multicolumn{2}{|c|}{2005} \\
\hline & $\mathrm{N}$ & $\%$ & $\mathrm{~N}$ & $\%$ \\
\hline Total & 5229 & 100 & 9717 & 100 \\
\hline \multicolumn{5}{|l|}{$\begin{array}{l}\text { Sedentary work ( } \geq 25 \text { hours } \\
\text { spent sitting at work per week) }\end{array}$} \\
\hline Yes & 1749 & 33.5 & 3365 & 34.6 \\
\hline No & 3480 & 66.5 & 6352 & 64.4 \\
\hline \multicolumn{5}{|l|}{ Age (years) } \\
\hline $21-39$ & 2359 & 45.1 & 3394 & 34.9 \\
\hline $40-49$ & 1398 & 26.7 & 2833 & 29.2 \\
\hline $50-59$ & 1202 & 23.0 & 2533 & 26.1 \\
\hline $60-69$ & 267 & 5.1 & 919 & 9.5 \\
\hline$\geq 70$ & 3 & 0.1 & 38 & 0.4 \\
\hline \multicolumn{5}{|l|}{ Gender } \\
\hline Women & 2584 & 49.4 & 5048 & 52.0 \\
\hline Men & 2645 & 50.6 & 4669 & 48.0 \\
\hline \multicolumn{5}{|l|}{ Socioeconomic status } \\
\hline Social class I (highest) & 811 & 15.5 & 1614 & 16.6 \\
\hline Social class II & 826 & 15.8 & 2095 & 21.6 \\
\hline Social class III & 1785 & 34.1 & 2656 & 27.3 \\
\hline Social class IV & 710 & 13.6 & 1572 & 16.1 \\
\hline Social class V (lowest) & 1097 & 21.0 & 1780 & 18.3 \\
\hline \multicolumn{5}{|l|}{ Smoking } \\
\hline Never smoker & 1937 & 37.0 & 2995 & 30.8 \\
\hline Former smoker & 1190 & 22.8 & 2564 & 26.4 \\
\hline Current smoker & 2102 & 40.2 & 4158 & 42.8 \\
\hline \multicolumn{5}{|l|}{ Leisure-time physical activity } \\
\hline$\geq 2 \mathrm{hr} / \mathrm{wk}$ of light intensity & 4480 & 85.7 & 8221 & 84.6 \\
\hline$<2 \mathrm{hr} /$ wk of light intensity & 749 & 14.3 & 1496 & 15.4 \\
\hline \multicolumn{5}{|l|}{$\begin{array}{l}\text { High alcohol consumer } \\
\text { (>14/21 units per week for } \\
\text { women/men) }\end{array}$} \\
\hline No & 4946 & 94.6 & 8463 & 87.1 \\
\hline Yes & 283 & 5.4 & 1254 & 12.9 \\
\hline \multicolumn{5}{|l|}{ Decision latitude } \\
\hline Always & 3026 & 57.9 & 4594 & 47.3 \\
\hline Usually & 1601 & 30.6 & 3717 & 38.3 \\
\hline Usually not & 283 & 5.4 & 875 & 9.0 \\
\hline Never & 319 & 6.1 & 531 & 5.5 \\
\hline \multicolumn{5}{|l|}{ Year of cohort entry } \\
\hline 2001 & 5229 & 100 & 5155 & 53.0 \\
\hline 2006 & 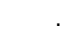 & . & 4562 & 47.0 \\
\hline
\end{tabular}

test served to check whether any non-linear relationship could be observed, which was not the case. Finally, we performed additional sensitivity tests for the two hypotheses including adjustments for health behaviors and decision latitude, which generated results that were consistent with the main analyses.

There may be several explanations that no associations between sedentary work and IHD could be observed in this study, despite moderate evidence for an existing association between general sedentary behavior and risk of heart disease in previous studies $(2,28)$. First, it is possible that sedentary work results in higher energy expenditure and includes more muscle contractions due to moderate arm movements compared to other sedentary behaviors, such as watching TV. This is
Table 3. Relative rate (RR) with $95 \%$ confidence interval $(95 \%$ $\mathrm{CI}$ ) for ischemic heart disease as a function of sedentary work and occupational sitting time, respectively, among employees in the Danish Work Environment Cohort Study (DWECS), 1991-2010 \& 2001-2010. [Ref=reference.]

\begin{tabular}{|c|c|c|c|c|}
\hline & \multicolumn{4}{|c|}{ Ischemic heart disease (IHD) } \\
\hline & $\begin{array}{l}\text { Person- } \\
\text { years }\end{array}$ & Cases & $\mathrm{RR}$ & $95 \% \mathrm{Cl}$ \\
\hline $\begin{array}{l}\text { Sedentary work }{ }^{\mathrm{a}}(\geq 25 \\
\mathrm{hr} / \text { wk spent sitting) }\end{array}$ & 47007 & 152 & 0.95 & $0.78-1.16$ \\
\hline Non-sedentary work & 98843 & 358 & Ref & \\
\hline $\begin{array}{l}\text { Sedentary work }{ }^{b}(\geq 25 \\
\text { hr/wk spent sitting) }\end{array}$ & 23323 & 64 & 0.94 & $0.71-1.27$ \\
\hline Non-sedentary work & 45336 & 152 & Ref & \\
\hline $\begin{array}{l}\text { Occupational sitting time a } \\
\text { (Per } 10 \mathrm{hr} / \text { wk increase) }\end{array}$ & 145850 & 510 & 0.99 & $0.92-1.06$ \\
\hline $\begin{array}{l}\text { Occupational sitting time }{ }^{b} \\
\text { (Per } 10 \mathrm{hr} / \text { wk increase) }\end{array}$ & 68659 & 216 & 0.98 & $0.88-1.09$ \\
\hline $\begin{array}{l}\text { adjusted for gender, age, } \\
\text { Follow-up period } 1991-20 \\
\text { b Sensitivity analyses adjust } \\
\text { smoking status, alcohol co } \\
\text { decision latitude and calen } \\
2000 \text { and } 2005 \text {. }\end{array}$ & $\begin{array}{l}\text { MI, socioec } \\
0 \text {, waves } 19 \\
\text { d for gende } \\
\text { nsumption, }\end{array}$ & $\begin{array}{l}\text { lomic st } \\
0,1995 \\
\text { age, soo }\end{array}$ & $\begin{array}{l}\text { and cal } \\
0 \text { and } 2 \\
\text { anomir }\end{array}$ & $\begin{array}{l}\text { ndar year. } \\
005 . \\
\text { status, } \\
\text { ctivity, }\end{array}$ \\
\hline
\end{tabular}

to some extent indicated in a study by Matthews et al (3), where time spent watching TV was associated with cardiovascular mortality, which was not the case for overall daily sitting time. Also, in a study investigating sedentary leisure-time behavior and the risk of cardiovascular disease, only 1.0 MET activities were included (10). Sedentary computer or desk work was set to 1.5 MET reflecting the authors' hypothesis that the health effects of sedentary work are distinct from that of general sedentary behavior. Second, Healy et al's research (29) demonstrated that not only the total amount of time spent sitting but also the manner in which it is accumulated is important for the effect on metabolic biomarkers. In general, sedentary work might very well involve more frequent interruptions than certain sedentary behaviors during leisure time, such as watching TV. Variations in the number and lengths of interruptions in sedentary work as well as the years of accumulated exposure should be considered in future studies investigating the potential adverse health effects of sedentary work.

This multi-wave cohort design has several strengths. Data on occupational sitting was collected before onset of IHD and purchase of IHD-related medication, and only respondents free from these clinical endpoints during the calendar year preceding baseline were included. The multiple measurements also reduce misclassification due to changes in exposure and confounder status during follow-up. However, since workers might seek more sedentary jobs as symptoms increase prior to the endpoint, it is possible that the effect has been overestimated.

By measuring occupational sitting as absolute sitting time, it was possible to disentangle its effect on risk of cardiovascular disease from that of occupational physi- 
Table 4. Relative rate $(\mathrm{RR})$ with $95 \%$ confidence interval $(95 \% \mathrm{CI})$ for purchase of ischemic heart disease (IHD)-related medication as a function of sedentary work and occupational sitting time, respectively, among employees in the Danish Work Environment Cohort Study, (DWECS) 1996-2010 and 2001-2010. [BMI=body mass index.]

\begin{tabular}{|c|c|c|c|c|c|c|c|c|}
\hline & \multicolumn{8}{|c|}{ IHD-related medication } \\
\hline & \multicolumn{4}{|c|}{ Men } & \multicolumn{4}{|c|}{ Women } \\
\hline & Person-years & Cases & $\mathrm{RR}$ & $95 \% \mathrm{Cl}$ & Person-years & Cases & $\mathrm{RR}$ & $95 \% \mathrm{Cl}$ \\
\hline $\begin{array}{l}\text { Sedentary worka ( } \geq 25 \text { hours per } \\
\text { week spent sitting) }\end{array}$ & 16188 & 455 & 1.00 & $0.88-1.13$ & 13032 & 373 & 0.93 & $0.82-1.06$ \\
\hline Non-sedentary work & 28761 & 808 & Ref. & & 29424 & 991 & Ref. & \\
\hline $\begin{array}{l}\text { Sedentary workb ( } \geq 25 \text { hours per } \\
\text { week spent sitting) }\end{array}$ & 10402 & 318 & 1.03 & $0.89-1.19$ & 8799 & 269 & 0.92 & $0.80-1.07$ \\
\hline Non-sedentary work & 17459 & 538 & Ref. & & 19375 & 673 & Ref. & \\
\hline $\begin{array}{l}\text { Occupational sitting timea (Per } \\
10 \mathrm{hr} / \text { wk increase) }\end{array}$ & 44949 & 1263 & 1.01 & $0.96-1.05$ & 42456 & 1364 & 0.98 & $0.93-1.03$ \\
\hline $\begin{array}{l}\text { Occupational sitting timeb (Per } \\
10 \mathrm{hr} / \text { wk increase) }\end{array}$ & 27861 & 856 & 1.03 & $0.98-1.08$ & 28174 & 942 & 0.97 & $0.91-1.02$ \\
\hline
\end{tabular}

${ }^{a}$ Adjusted for age, BMI, socioeconomic status and calendar year. Follow-up period 1996-2010, waves 1995, 2000 and 2005.

${ }^{\text {b }}$ Sensitivity analyses adjusted for age, socioeconomic status, smoking status, alcohol consumption, leisure time physical activity, decision latitude and calendar year. Follow-up period: 2001-2010, waves 2000 and 2005.

cal activity. Several previous studies have been challenged by using a measure of occupational sitting level that was included in a categorical scale of occupational physical activity $(15,30-35)$, which is not in line with the two behaviors being distinct risk factors.

Literature on general sedentary behavior suggests a strong dose-response relationship with cardiovascular disease (11). Yet, high physical demands at work are also shown to be associated with increased risk of cardiovascular morbidity and mortality (33). High physical demands are likely to be present among employees with low levels of occupational sitting time, which could have led to the alternative hypothesis of a u-shaped relationship between occupational sitting and IHD. However, the results of the present study did not confirm any non-linear relationship.

Information on the two outcome measures - IHD and IHD-related medication - are derived from national registers considered to be of high validity (20). However, prescription and detection biases related to IHD might be present. Health staff must take into account the number of risk factors of cardiovascular disease present in a patient when deciding whether or not to prescribe drug treatment for hypertension and high cholesterol levels (36). Since people engaged in sedentary work tend to represent socioeconomic groups, where these risk factors are less prevailing, an underestimation of the detrimental effect of sedentary work may be expected when studying IHD-related medication as a proxy for IHD. In contrast, these biases may be reversed by detection bias as people engaged in sedentary work might be more prone to make an unsolicited appointment for a health check-up (17).

A limitation of the study is the use of the selfreported measure of occupational sitting, which has not been validated. Though imprecise, other workplace sitting measures have been shown to have acceptable properties for use in observational studies $(37,38)$.

This study could not confirm the hypothesis that sedentary work is a distinct risk factor for IHD. Neither was it confirmed that a dose-response relationship exists between occupational sitting time and the risk of IHD. Future studies should further investigate associations between objectively measured occupational sitting time and IHD.

\section{References}

1. Sedentary Behaviour RN. Letter to the editor: standardized use of the terms "sedentary" and "sedentary behaviors". Appl Physiol Nutr Metab. 2012;37:540-2. http://dx.doi. org/10.1139/h2012-024.

2. Proper KI, Singh AS, van Mechelen W, Chinapaw MJM Sedentary Behaviors and Health Outcomes Among Adults: A Systematic Review of Prospective Studies. Am J Prev Med. 2011;40:174-82. http://dx.doi.org/10.1016/j. amepre.2010.10.015.

3. Matthews CE, George SM, Moore SC, Bowles HR, Blair A, Park Y, et al. Amount of time spent in sedentary behaviors and cause-specific mortality in US adults. Am J Clin Nutr. 2012;95:437-45. http://dx.doi.org/10.3945/ajcn.111.019620.

4. Wilmot EG, Edwardson CL, Achana FA, Davies MJ, Gorely T, Gray LJ, et al. Sedentary time in adults and the association with diabetes, cardiovascular disease and death: systematic review and meta-analysis. Diabetologia. 2012;55:2895-905. http://dx.doi.org/10.1007/s00125-012-2677-z.

5. Cong YJ, Gan Y, Sun HL, Deng J, Cao SY, Xu X, et al. Association of sedentary behavior with colon and rectal cancer: a meta-analysis of observational studies. Br J Cancer. 2014;110:817-26. http://dx.doi.org/10.1038/bjc.2013.709. 
6. Petersen CB, Bauman A, Grønbæk M, Helge JW, Thygesen LC, Tolstrup JST. Total sitting time and risk of myocardial infarction, coronary heart disease and all-cause mortality in a prospective cohort of Danish adults. Int J Behav Nutr Phys Act. 2014 Feb 5;11:13. http://dx.doi.org/10.1186/1479-586811-13.

7. Hamilton M, Healy G, Dunstan D, Zderic T, Owen N. Too little exercise and too much sitting: Inactivity physiology and the need for new recommendations on sedentary behavior. Curr Cardiovasc Risk Rep. 2008;2:292-8. http://dx.doi. org/10.1007/s12170-008-0054-8.

8. Dunstan DW, Howard B, Healy GN, Owen N. Too much sitting - A health hazard. Diabetes Res Clin Pract Suppl. 2012;97:36876. http://dx.doi.org/10.1016/j.diabres.2012.05.020.

9. Aadahl M, Kjær M, Jørgensen T. Influence of time spent on TV viewing and vigorous intensity physical activity on cardiovascular biomarkers. The Inter 99 study. Eur J Cardiovasc Prev Rehabil. 2007;14:660-5. http://dx.doi. org/10.1097/HJR.0b013e3280c284c5.

10. Frydenlund G, Jørgensen T, Toft U, Pisinger C, Aadahl M. Sedentary leisure time behavior, snacking habits and cardiovascular biomarkers: the Inter99 Study. Eur J Prev Cardiol. 2012;19:1111-9. http://dx.doi. org/10.1177/1741826711419999.

11. Grøntved A, Hu F. Television viewing and risk of type 2 diabetes, cardiovascular disease, and all-cause mortality: A meta-analysis. JAMA. 2011;305:2448-55. http://dx.doi. org/10.1001/jama.2011.812.

12. Stamatakis E, Hamer M, Dunstan DW. Screen-Based Entertainment Time, All-Cause Mortality, and Cardiovascular Events: Population-Based Study With Ongoing Mortality and Hospital Events Follow-Up. J Am Coll Cardiol. 2011;57:2929. http://dx.doi.org/10.1016/j.jacc.2010.05.065.

13. Saidj M, Jørgensen T, Jacobsen R, Linneberg A, Aadahl M. Separate and joint associations of occupational and leisuretime sitting with cardio-metabolic risk factors in working adults: a cross-sectional study. PLOS One. 2013;8. http:// dx.doi.org/10.1371/journal.pone.0070213.

14. Pinto Pereira SM, Ki M, Power C. Sedentary Behaviour and Biomarkers for Cardiovascular Disease and Diabetes in MidLife: The Role of Television-Viewing and Sitting at Work. PLOS One. 2012;7:1-9. http://dx.doi.org/10.1371/journal. pone. 0031132 .

15. van Uffelen JGZ, Wong J, Chau JY, van der Ploeg HP, Riphagen I, Gilson ND, et al. Occupational Sitting and Health Risks: A Systematic Review. Am J Prev Med. 2010;39:379-88. http://dx.doi.org/10.1016/j.amepre.2010.05.024.

16. Yates T, Wilmot EG, Davies MJ, Gorely T, Edwardson C, Biddle S, et al. Sedentary Behavior: What's in a Definition? Am J Prev Med. 2011;40:e33-4. http://dx.doi.org/10.1016/j. amepre.2011.02.017.

17. Hannerz H, Dalhoff K, Burr H, Latza U. Correlation between relative rates of medication for IHD and relative rates of hospital treatment or death due to IHD among occupational and industrial groups in Denmark, 1996-2005. Int J Occup Med Environ Health. 2014;27:536-46. http://dx.doi. org/10.2478/s13382-014-0276-6.

18. Feveile H, Olsen O, Burr H, Bach E. The Danish Work Environment Cohort Study 2005: From idea to sampling design. Statistics in Transition - new series. 2007;8:441-58.

19. Lynge E, Sandegaard JL, Rebolj M. The Danish National Patient Register. Scand J Public Health. 2011;39:30-33. http:// dx.doi.org/10.1177/1403494811401482.

20. Kildemoes HW, Toft Sørensen H, Hallas J. The Danish National Prescription Registry. Scand J Public Health. 2011;39:38-41. http://dx.doi.org/10.1177/1403494810394717.

21. Eriksen D, Rosthøj S, Burr H, Holtermann A. Sedentary work Associations between five-year changes in occupational sitting time and body mass index. Prev Med. 2015;73:1-5. http:// dx.doi.org/10.1016/j.ypmed.2014.12.038.

22. Carr LJ, Karvinen K, Peavler M, Smith R, Cangelosi K. Multicomponent intervention to reduce daily sedentary time: a randomised controlled trial. BMJ Open. 2013;3. http://dx.doi. org/10.1136/bmjopen-2013-003261.

23. Hannerz H, Dalhoff,K, Burr,H, Latza,U Correlation between relative rates of medication for IHD and relative rates of hospital rteatment or death due to IHD among occupational and industrial groups in Denmark, 1996-2005. Int J Occup Med Environ Health. 2014;27(4):536-46. http://dx.doi. org/10.2478/s13382-014-0276-6.

24. Glymour MM, Greenland S. Causal Diagrams. In. Modern epidemiology. Philadelphia, PA: Wolters Kluwer; 2008. p. 183-209.

25. Borg V, Kristensen TS. Social class and self-rated health: can the gradient be explained by differences in life style or work environment. Soc Sci Med. 2000;51:1019-30. http://dx.doi. org/10.1016/S0277-9536(00)00011-3.

26. Danish Health and Medicines Authority. Alcohol. Our 7 recommendations about alcohol. Copenhagen: Danish Health and Medicines Authority; updated 21 January 2014.

27. Pejtersen JH, Burr H, Hannerz H, Fishta A, Hurwitz EN. Update on work-related psychosocial factors and the development of ischemic heart disease: a systematic review. Cardiol Rev. 2015;23:94-8. http://dx.doi.org/10.1097/ CRD.0000000000000033.

28. Ford ES, Caspersen CJ. Sedentary behavior and cardiovascular disease: a review of prospective studies. Int $\mathrm{J}$ Epidemiol. 2012;41:1338-53. http://dx.doi.org/10.1093/ije/dys078.

29. Healy GN, Dunstan D, Salmon J, Cerin E, Shaw JE, Zimmet $\mathrm{PZ}$, et al. Breaks in sedentary time: beneficial associations with metabolic risk. Diabetes Care. 2008;31:661-6. http://dx.doi. org/10.2337/dc07-2046.

30. Held C, Iqbal R, Lear SA, Rosengren A, Islam S, Mathew J, et al. Physical activity levels, ownership of goods promoting sedentary behavior and risk of myocardial infarction: results of the INTERHEART study. Eur Heart J. 2012;33:452-66. http:// dx.doi.org/10.1093/eurheartj/ehr432.

31. $\mathrm{Hu} \mathrm{G}$, Tuomilehto J, Borodulin K, Jousilahti P. The joint associations of occupational, commuting, and leisure-time physical activity, and the Framingham risk score on the 10year risk of coronary heart disease. Eur Heart J. 2007;28. http://dx.doi.org/10.1093/eurheartj/ehl475. 
32. Frost L, Frost P, Vestergaard P. Work related physical activity and risk of a hospital discharge diagnosis of atrial fibrillation or flutter: the Danish Diet, Cancer, and Health Study. Occup Environ Med. 2005;62:49-53. http://dx.doi.org/10.1136/ oem.2004.014266.

33. Moe B, Mork PJ, Holtermann A, Nilsen TIL. Occupational physical activity, metabolic syndrome and risk of death from all causes and cardiovascular disease in the HUNT 2 cohort study. Occup Environ Med. 2013;70:86-90. http://dx.doi. org/10.1136/oemed-2012-100734.

34. Holtermann A, Marott JL, Gyntelberg F, S`gaard K, Suadicani $\mathrm{P}$, Mortensen OS, et al. Occupational and leisure time physical activity: risk of all-cause mortality and myocardial infarction in the Copenhagen City Heart Study. A prospective cohor study. BMJ Open. 2012;13:2(1):e000556.http://dx.doi. org/10.1136/bmjopen-2011-000556.

35. Mozumdar A, Liguori G. Occupational Physical Activity and the Metabolic Syndrome Among Working Women: A Go Red North Dakota Study. J Phys Act Health. 2011;8:321-31.
36. Task FM, Perk J, De Backer G, Gohlke H, Graham I, Reiner $Z$, et al. European Guidelines on cardiovascular disease prevention in clinical practice (version 2012): The Fifth Joint Task Force of the European Society of Cardiology and Other Societies on Cardiovascular Disease Prevention in Clinical Practice (constituted by representatives of nine societies and by invited experts). Developed with the special contribution of the European Association for Cardiovascular Prevention \& Rehabilitation (EACPR). Eur Heart J. 2012.

37. Lagersted-Olsen J, Korshoj M, Skotte J, Carneiro IG, Sogaard K, Holtermann A. Comparison of objectively measured and self-reported time spent sitting. Int J Sports Med. 2014;35:534-40.

38. Clark BK, Thorp AA, WINKLER AH, Gardiner PA, Healy GN, Owen N, et al. Validity of Self-Reported Measures of Workplace Sitting Time and Breaks in Sitting Time. Official Journal of the American College of Sports Medicine. 2011;43:1907-12.

Received for publication: 13 March 2015 